\title{
DESENVOLVIMENTO DE NOVO PRODUTO DE CACAU COM ADIÇÃO DE NOZES DE MACADÂMIA MALTADAS
}

\author{
L. V. MARIM ${ }^{1 *}$, F. M. R. SILVA ${ }^{2}$, L. S. ARRIECHE ${ }^{3}$, D. J. M. SARTORI ${ }^{4}$ \\ ${ }^{1}$ Bolsista PIBIC, Universidade Federal do Espírito Santo (DETEC/CEUNES) \\ ${ }^{2}$ Aluno de Engenharia Química, Universidade Federal do Espírito Santo (DETEC/CEUNES) \\ ${ }^{3}$ Professor, Universidade Federal do Espírito Santo (DETEC/CEUNES) \\ ${ }^{4}$ Professor, Universidade Federal de São Carlos (DEQ/CCET) \\ *E-mail para contato: layravalani@gmail.com
}

\begin{abstract}
RESUMO - A macadâmia e o cacau são frutos em pleno desenvolvimento no Espírito Santo. Em vista disso, o cerne deste trabalho foi a produção do malte da amêndoa de macadâmia para enquadrá-lo na formulação de um novo produto de cacau. Separaram-se as sementes de macadâmia em dois lotes distintos. As nozes do primeiro lote sofreram quebra de dormência por rachadura na casca, maceração por 96 horas e germinação em sacola plástica transparente umedecida por 30 dias. O segundo lote foi subdivido quanto à quebra de dormência e maturação das sementes. A quebra de dormência ocorreu por imersão em água fervente. A maceração durou 24 horas, seguida da germinação em algodão úmido por 30 dias. As amêndoas foram secas e torradas. O índice germinativo visível mais expressivo foi de 2,86\% referente às sementes maduras do segundo lote. Todavia, a secagem e a torrefação evidenciaram a formação de açúcares redutores nas nozes maltadas. $\mathrm{O}$ estudo foi relevante para a exploração do processo de maltagem de amêndoas em geral.
\end{abstract}

\section{INTRODUÇÃO}

No Brasil, a região sudeste é a principal produtora de macadâmia, sendo os estados de maior produção São Paulo e Espírito Santo (Penoni, 2011). A amêndoa inteira é o principal produto comercial. É consumida crua, torrada ou no preparo de bombons finos. Já as amêndoas quebradas durante o processamento ou de qualidade inferior são utilizadas para extração de óleo de excelente qualidade, utilizado principalmente na fabricação de cosméticos e indústria farmacêutica (Pimentel, 2007). Além da macadâmia, o Espírito Santo se destaca como o terceiro maior produtor de cacau do Brasil (Espírito Santo, 2014).

Antes de serem consumidos, a maior parte dos alimentos passa por processamento térmico, o que garante a segurança microbiológica, a inativação de algumas enzimas, a degradação de substâncias tóxicas e, ainda, o desenvolvimento de substâncias responsáveis pelo aroma, cor e sabor, melhorando a sua palatabilidade. Essas substâncias (compostos denominados genericamente de Produtos da Reação de Maillard - PRM) são características da Reação de Maillard (RM), que ocorre durante o processamento térmico e/ou armazenamento prolongado de alimentos que contêm proteínas e açúcares redutores (Finot; Friedman; Nunes \& Baptista, apud Shibao; Bastos, 2011, p. 896). Segundo Damodaran et al. (2010), o 
escurecimento de alimentos sob aquecimento ocorre devido a reações químicas entre o açúcar redutor, principalmente a D-glicose, e um grupo amina primário.

As proteínas são encontradas em todos os tecidos das sementes, apresentando-se em maiores concentrações no embrião (Carvalho; Nakagava, 2000). Segundo Simmonds \& Orth (apud Carvalho; Nakagava, 2000, p. 83), as enzimas (fração das proteínas) são ativadas em sementes em germinação. De modo genérico, a maltagem é uma germinação controlada, seguida pela secagem controlada de uma semente (Hoseney, apud Miranda, 2006, p. 3). Na maltagem, empenha-se em minimizar o crescimento da semente para evitar a perda de açúcares, causada pelo crescimento e respiração. Ao mesmo tempo é maximizada a degradação do endosperma e a formação de enzimas (Munck, apud Miranda, 2006, p. 3).

Neste contexto, objetivou-se a produção do malte da amêndoa de macadâmia a fim de enquadrá-lo na formulação de um novo produto de cacau, beneficiando da regionalidade de ambos os frutos.

\section{MATERIAL E MÉTODOS}

Utilizaram-se sementes de macadâmia fornecidas pela Cooperativa Agroind dos Produtores de Noz Macadâmia (COOPMAC), localizada na cidade de São Mateus - ES. Os frutos foram colhidos num raio aproximado de $25 \mathrm{~km}$ da cidade, nos meses de outubro/2013 e dezembro/2013. Foram coletadas sementes verdes e maduras. Após serem apanhadas e lavadas manualmente, as sementes foram transportadas até o laboratório de eficiência energética do Prédio de Pós-Graduação em Energia - UFES (CEUNES).

\subsection{Quebra de Dormência, Maceração e Germinação}

Conforme Carvalho e Nakagava (2000), a casca contém substâncias que muitas vezes impede a entrada de água no interior da semente quando esta é colocada em condições adequadas para a germinação. Logo, para que o processo germinativo se desencadeasse com maior velocidade foi necessária a quebra de dormência das sementes.

O primeiro lote consistiu em 74 frutos maduros colhidas no mês de outubro/2013. Estes sofreram quebra de dormência por uma pequena rachadura na casca através de um martelo e pinça metálica. Imersas em vasilhas de plástico com água a temperatura ambiente, maceraram por 96 horas. Em seguida, foram escoadas e postas para germinar durante 30 dias em sacolas plásticas transparentes, parcialmente fechadas, umedecidas e expostas ao sol matinal.

O segundo lote foram os frutos colhidos no mês de dezembro/2013 consistindo em 79 sementes verdes e 70 sementes maduras. Destas, a metade, 39 sementes verdes e 35 sementes maduras sofreram quebra de dormência por imersão em água a $100^{\circ} \mathrm{C}$ e deixadas esfriar até que se atingisse a temperatura ambiente. Posteriormente, as 140 sementes foram imersas em água à temperatura ambiente e maceradas por 24 horas. Após um período de 12 horas houve troca da água. A germinação foi realizada em duas vasilhas de plástico, uma para as sementes verdes e a outra para as sementes maduras. Em cada vasilha, as sementes com quebra de dormência foram separadas por uma distância de $10 \mathrm{~cm}$ das sementes sem quebra de 
dormência. Todas foram envolvidas em algodão umedecido com água e expostas à luz solar e ao ar livre por um período de 30 dias. Aos primeiros indícios de broto, as amêndoas foram extraídas da casca e congeladas a $-18^{\circ} \mathrm{C}$, em diferentes sacolas plásticas para posterior secagem e torrefação.

\subsection{Preparação das Amostras para Secagem}

Sementes verdes e maduras do segundo lote, com quebra de dormência, com e sem broto foram selecionadas e separadas em três conjuntos distintos. A massa de cada conjunto foi medida e cada um dos seus elementos fotografados. Em seguida, as amostras foram colocadas em uma estufa de secagem por convecção natural (modelo S250SD) a $70{ }^{\circ} \mathrm{C}$, onde permaneceram em intervalos de 15 minutos. O procedimento foi repetido até que a variação da massa não fosse significativa. Para a determinação da umidade de equilíbrio, as amostras permaneceram dentro da estufa a $105^{\circ} \mathrm{C}$ por aproximadamente 12 horas.

\subsection{Preparação das Amostras para Torrefação}

Sementes verdes e maduras, com e sem quebra de dormência (CQD e SQD, respectivamente), com e sem broto foram selecionadas, separas em seis amostras distintas e torradas durante 5 horas e 30 minutos em estufa (modelo S250SD) a $115^{\circ} \mathrm{C}$. No início e após cada 30 minutos, as amêndoas eram fotografadas para o registro da cor e analisado sensorialmente a intensidade do aroma desenvolvido. O processo foi iterado até que não houvesse mais alteração nessas características.

\section{RESULTADOS E DISCUSSÃO}

\subsection{Quebra de Dormência, Maceração e Germinação}

A quebra de dormência no primeiro lote não foi satisfatória, visto que algumas sementes foram danificadas com o martelo. $\mathrm{O}$ tempo de maceração prolongado provocou escurecimento da água e odor desagradável. As sementes desenvolveram fungos no interior das sacolas plásticas e precisaram ser descartadas. O índice germinativo foi nulo.

No segundo lote, a quebra de dormência por imersão em água à $100{ }^{\circ} \mathrm{C}$ foi viável por apresentar baixo custo e rapidez. Nenhuma semente foi danificada neste processo. $\mathrm{O}$ tempo de maceração foi satisfatório visto que a água não apresentou alteração de cor nem odor. Entretanto, a renovação da água foi importante para que se conservasse a temperatura. Entre as sementes maduras postas para germinar, apenas uma apresentou broto interno e outra exibiu broto externo. Assim, o índice germinativo foi de 2,86\%. Entre as sementes verdes em germinação, apenas uma exibiu broto externo, configurando índice germinativo de 1,27\%.

A Figura 1 mostra o broto externo de uma semente verde de macadâmia, obtida por meio dos experimentos. Na Figura 2 observa-se o broto externo de uma semente madura. 
Figura 1 - Broto externo de uma semente verde de macadâmia.

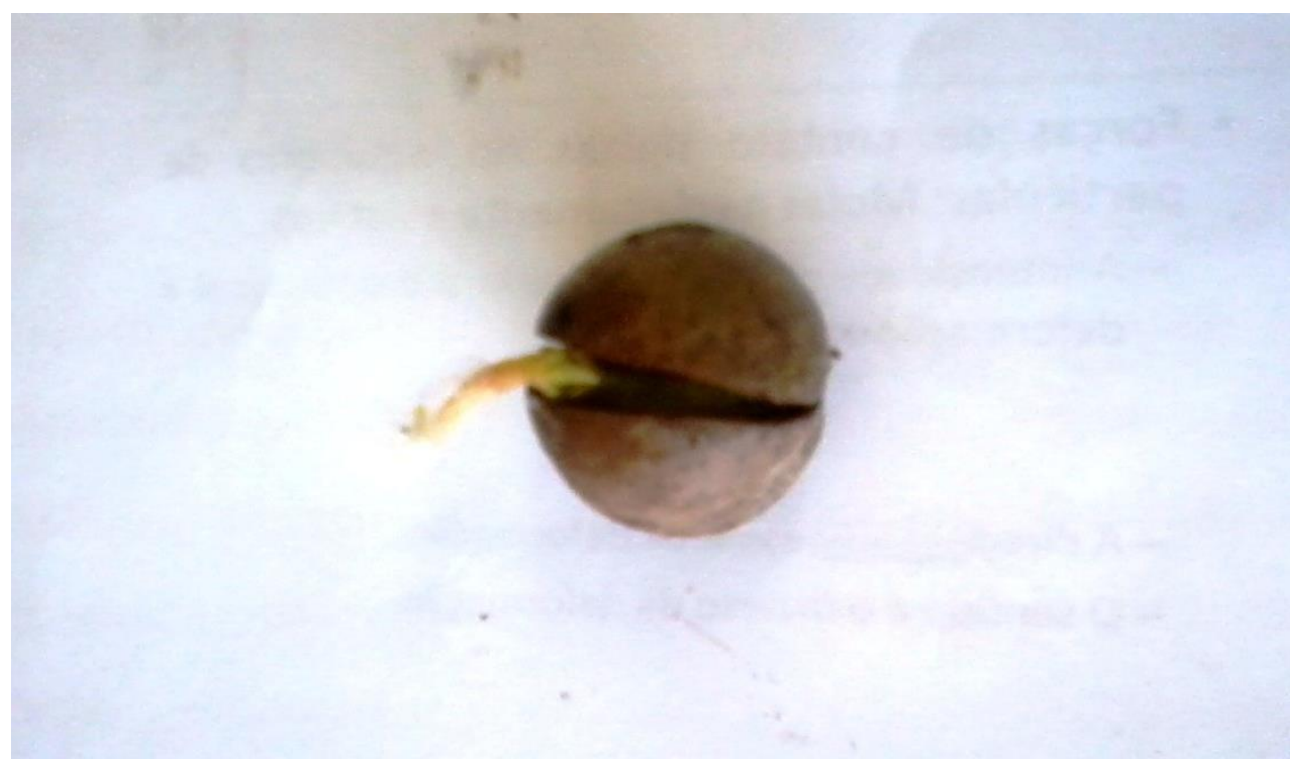

Figura 2 - Broto externo de uma semente madura de macadâmia.

\subsection{Secagem}

Oriundas do segundo lote, foram analisadas dois tipos de sementes de macadâmia: sementes verdes e maduras com quebra de dormência, com e sem broto. Ambos os tipos de sementes foram secas por convecção natural, nas mesmas condições, em uma estufa a $70^{\circ} \mathrm{C}$. As Figuras 3 e 4 mostram o comportamento típico do raio no decorrer do período de secagem. 


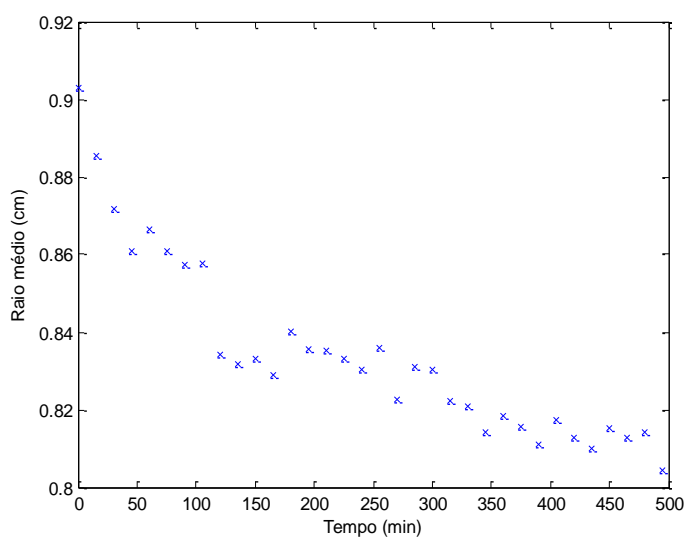

Figura 3 - Redução do raio durante a secagem em sementes verdes com quebra de dormência e sem broto.

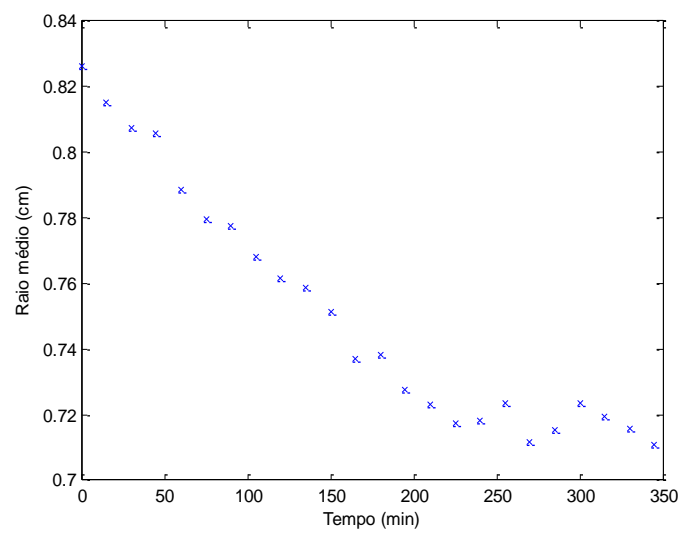

Figura 4 - Redução do raio durante a secagem em sementes maduras com quebra de dormência e sem broto.

A redução do raio da amostra ocorre devido à perda de massa durante a secagem. A migração de água do interior para a superfície causa uma deformação nas estruturas internas da amostra e, consequentemente, seu encolhimento. A partir da Figura 3 observa-se uma redução acentuada do raio durante os primeiros 200 minutos de secagem. Após este período, redução torna-se lenta e tende a $0,81 \mathrm{~cm}$. Na Figura 4 este valor se aproxima de $0,71 \mathrm{~cm}$.

O comportamento da densidade do fluxo de massa para ambas as sementes é descrito pelas Figuras 5 e 6. Na Figura 5, observa-se que o primeiro período decrescente de secagem é mais longo em relação à Figura 6. Isso é pode ser explicado pelos conteúdos inciais diferentes de água das sementes.

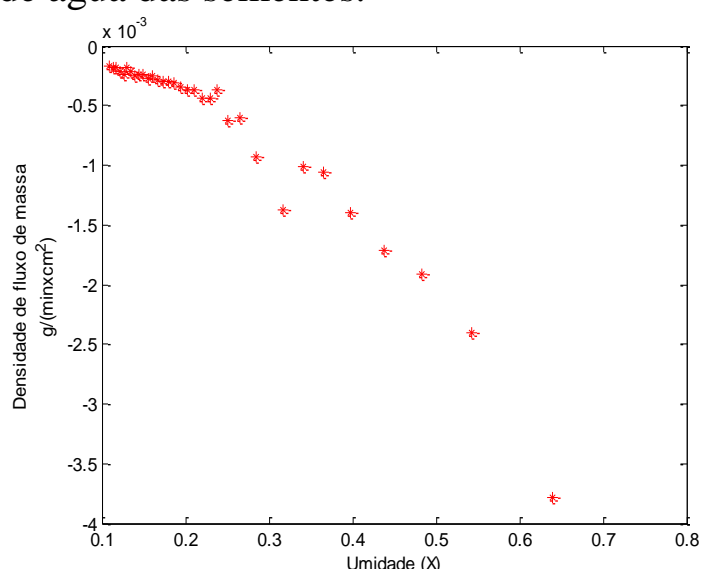

Figura 5 - Densidade de fluxo de massa em função da umidade em sementes verdes com quebra de dormência e sem broto.

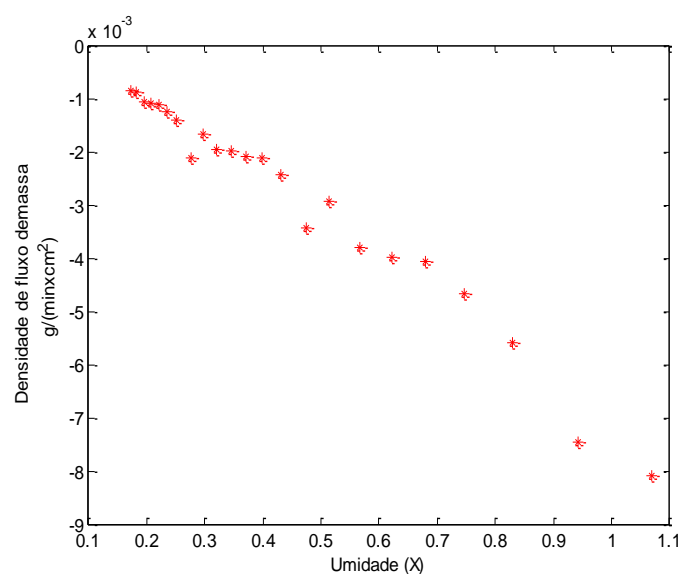

Figura 6 - Densidade de fluxo de massa em função da umidade em sementes maduras com quebra de dormência e sem broto.

Pela análise da inclinação da curva no gráfico de densidade de fluxo de massa por umidade, a secagem das sementes descritas neste trabalho caracterizou-se por dois períodos predominantes de taxa descrescente de secagem. Para a fase de taxa decrescente de secagem, o produto não se comporta como se estivesse recoberto por uma fina camada de água (Guimarães, 2005), pois a migração de água do interior do sólido para a superfície é insuficiente para compensar a perda de umidade por evaporação. No primeiro período 
drecescente ainda há umidade livre presente na amostra. Normalmente ocorre a formação de aglomerações descontínuas de água livre por toda a superfície (Zhang, 1999). O conteúdo de água livre na superficie influencia os coeficientes de tranferência de calor e de massa, causando uma redução umidade mais acentuda (pela existência de água livre na superfície) e um aumento de temperatura um pouco mais lento em relação ao segundo período decrescente de secagem.

O segundo período decrescente da secagem caracteriza-se pela ausência de água livre na superfície da amostra. A troca de calor não é mais compensada, conseqüentemente, a temperatura do produto aumenta mais rapidademente e tende assintoticamente à temperatura do ar. Durante todo este período o fator limitante é a migração interna de água (Park, 2007).

As Figuras 7 e 8 mostram a perda de umidade durante a secagem. Em ambas figuras, é possível verificar dois períodos predominantes diferentes de secagem. A diferença nos tempos em que esses períodos começam ou terminam é devido às diferenças das propriedades iniciais das amostras. Nas figuras abaixo, $\mathrm{X}$ representa a umidade da amostra em $\mathrm{g}$ de água por $\mathrm{g}$ de amostra seca.

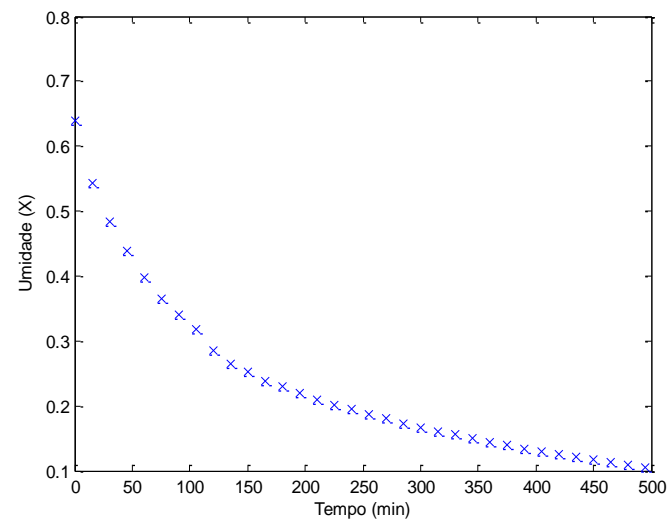

Figura 7 - Perda de umidade durante a secagem em sementes verdes com quebra de dormência e sem broto.

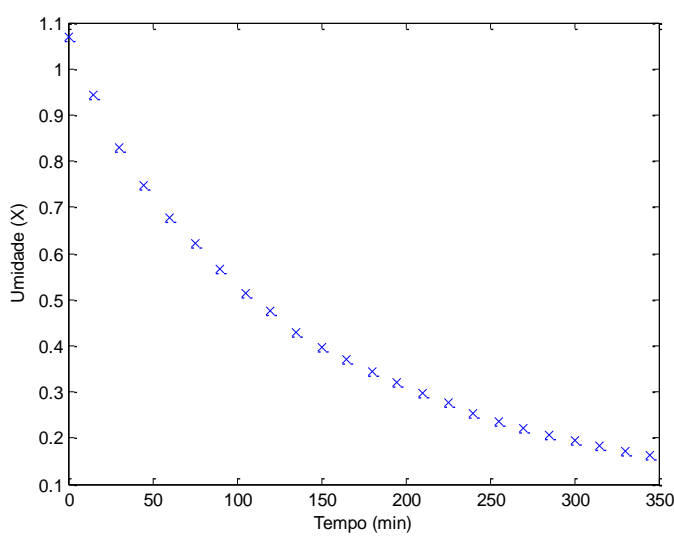

Figura 8 - Perda de umidade durante a secagem em sementes maduras com quebra de dormência e sem broto.

\subsection{Torrefação}

A torrefação evidenciou o desencadeamento do processo germinativo na maioria das sementes, visto que a reação de Maillard atuou sobre os açúcares redutores formados durante esse processo, produzindo substâncias responsáveis pela cor e aroma das amêndoas maltadas. Isto explica o fato das amêndoas maltadas terem exibido coloração marrom e odor bastante adocicado bem mais intensos que as não maltadas (Quadro 1). A reação de Maillard atuou mais veemente sobre as amêndoas maltadas verdes e as amêndoas maltadas maduras sem quebra de dormência e sem broto externo.

A temperatura de $115^{\circ} \mathrm{C}$ proporcionou maior velocidade da reação de Maillard e foi inferior a $120^{\circ} \mathrm{C}$, temperatura mínima necessária para a formação de acrilamida, substância neurotóxica encontrada em alimentos aquecidos a altas temperaturas (Damodaran et al., 2010). O tempo de 270 minutos de torra foi satisfatório, visto que a partir deste momento a cor e o aroma das amêndoas maltadas e não maltadas se tornaram constantes. 
Quadro 1 - Avaliação da cor das amêndoas de macadâmia maltadas e não maltadas em função do tempo durante o processo de torrefação

\begin{tabular}{|c|c|c|c|c|c|c|c|}
\hline \multirow{3}{*}{$\begin{array}{l}\text { Tempo } \\
\text { (min) }\end{array}$} & $\begin{array}{c}\text { Sementes } \\
\text { Não }\end{array}$ & \multicolumn{6}{|c|}{ Sementes Maltadas } \\
\hline & Sementes & \multicolumn{3}{|c|}{ Sementes Verdes } & \multicolumn{3}{|c|}{ Sementes Maduras } \\
\hline & SQD & $\begin{array}{c}\text { SQD } \\
\text { Sem Broto }\end{array}$ & $\begin{array}{c}\text { CQD } \\
\text { Sem Broto }\end{array}$ & $\begin{array}{c}\text { SQD } \\
\text { Com Broto } \\
\text { Externo } \\
\end{array}$ & $\begin{array}{c}\text { SQD } \\
\text { Sem Broto }\end{array}$ & $\begin{array}{c}\text { CQD } \\
\text { Com Broto } \\
\text { Interno } \\
\end{array}$ & $\begin{array}{c}\text { SQD } \\
\text { Com Broto } \\
\text { Externo }\end{array}$ \\
\hline 0 & & & & & & & \\
\hline 30 & & & & & & & \\
\hline 60 & & & & & & & \\
\hline 90 & & & & & & & \\
\hline 120 & & & & & & & \\
\hline 150 & & & & & & & \\
\hline 180 & & & & & & & \\
\hline 210 & & & & & & & \\
\hline 240 & & & & & & & \\
\hline 270 & & & & & & & \\
\hline 300 & & & & & & & \\
\hline 330 & & & & & & & \\
\hline
\end{tabular}

\section{CONCLUSÃO}

A secagem do malte de macadâmia ocorre durante o período de taxa decrescente, apresentando tempos distintos para sementes verdes e maduras. Em função do índice germinativo, a produção do malte das sementes de macadâmia foi mais satisfatória com o uso 
de sementes maduras sem quebra de dormência. Entretanto, como a disparidade neste valor foi muito pequena, e a cor e o aroma foram praticamente iguais nas amêndoas verdes sem quebra de dormência, considera-se que estas também são viáveis para a produção do malte de macadâmia. A reação de Maillard ocorreu de forma mais intensa sobre as amêndoas maltadas, desenvolvendo substâncias responsáveis pelo aroma, cor e sabor. Isto implica no possível desenvolvimento de um novo produto de cacau com adição de nozes de macadâmias maltadas.

\section{REFERÊNCIAS}

CARVAlHO, N. M. de; NAKAGAVA, J. Sementes: ciência, tecnologia e produção. 4 ed. Jaboticabal: Funep, 2000.

DAMODARAN, S.; PARKIN, K. L.; FENNEMA, O. R. Química de alimentos de Fennema. 4 ed. Porto Alegre: Artmed, 2010.

ESPÍRITO SANTO. Governo investe na recuperação de lavouras de cacau no Norte do ES. Vtória: Assessoria de Comunicação/Seag, 2 de maio 2014. Seção Notícias. Disponível em: < http://www.idaf.es.gov.br/WebForms/wfNoticia.aspx?cd_Noticia=814 >. Acesso em: 2 maio de 2014.

GUIMARÃES, D. S. Desenvolvimento de módulo computacional para a secagem estacionária de sementes. 2005. 165 f. Tese (Doutorado) - Ciência e Tecnologia de Sementes, Faculdade de Agronomia Eliseu Maciel, Universidade Federal de Pelotas, Pelotas, 2005.

MIRANDA, M. Z. de. Trigo: germinação e posterior extrusão para obtenção de farinha integral extrusada de trigo germinado. Passo Fundo: Embrapa Trigo, 2006. 12 p. html. (Embrapa Trigo. Documentos Online, 74). Disponível em: <www.cnpt.embrapa.br/biblio/do/p_do74.htm>. Acesso em: 24 abril 2014.

PARK, K. J.; ANTONIO, G. C.; OLIVEIRA, R. A. de. Conceitos de processo e equipamentos de secagem. Ct\&ea, Campinas, p. 1-127, 2007.

PENONI, E. S. Caracterização produtiva física e química de cultivares de nogueiramacadâmia. 2011. Tese (Doutorado) - Universidade Federal de Lavras, Lavras 2011.

PIMENTEL, L. D. A cultura da macadâmia. Revista Brasileira de Fruticultura. Jaboticabal, v. 29, n. 3, p. 414-716, 2007.

SHIBAO, J.; BASTOS, D. H. M. Produtos da reação de Maillard em alimentos: implicações para a saúde. Revista de Nutrição, Campinas, v. 6, n. 24, p. 895-904, 2011.

ZANG, Z.; YANG, S.; DENGYING, L. Mechanism and mathematical model of heat and mass transfer. Journal of chemical industry and engineering, China, p. 52-59, 05 jun. 1999. 